\title{
RECIDIVA TUMORAL EN LA ZONA DE RESECCIÓN DEL MEATO URETERAL TRAS DESINSERCIÓN ENDOSCÓPICA EN LA NEFROURETERECTOMÍA RADICAL
}

\author{
D. PASCUAL REGUEIRO, A. GARCÍA DE JALÓN MARTÍNEZ, C. SANCHO SERRANO, \\ E. MALLÉN MATEO, M. BLAS MARÍN, L.A. RIOJA SANZ
}

Servicio de Urología. Hospital Universitario Miguel Servet. Zaragoza.

Actas Urol Esp. 27 (4): 308-311, 2003

\section{RESUMEN}

"RECIDIVA TUMORAL EN LA ZONA DE RESECCIÓN DEL MEATO URETERAL TRAS DESINSERCIÓN ENDOSCÓPICA EN LA NEFROURETERECTOMÍA RADICAL"

La resección endoscópica del uréter en la nefroureterectomía radical es una forma sencilla en el tratamiento del carcinoma de células transicionales del tracto urinario superior. Queremos presentar una complicación derivada de la técnica quirúrgica: la recidiva tumoral en la zona de resección del meato ureteral.

PALABRAS CLAVE: Nefroureterectomía radical. Desinserción endoscópica.

\section{ABSTRACT}

"TUMOR IMPLANTATION IN RESECATED URETHERAL MEATUS ZONE AFTER ENDOSCOPIC RESECTION OF THE URETHER IN RADICAL NEPHROURETERECTOMY"

The endoscopical resection of the urether in the radical nephroureterectomy is an easy way for the treatment of the transicional cell carcinoma of the upper urinary tract.

We want to present a complication derivated of this chirurgical technique: the tumor implantation in the resecated ureteral meatus zone.

KEY WORDS: Radical nephroureterectomy. Endoscopical resection.

$\mathrm{L}$ a desinserción endoscópica del uréter como primer tiempo quirúrgico en la nefroureterectomía radical, es una técnica ampliamente descrita y usada en el tratamiento radical de los carcinomas uroteliales de tracto urinario superior.

Como puntos a favor de la misma se encuentran:

- La sencillez de realización.

- Acortamiento del tiempo quirúrgico.

- Menor morbilidad, al evitar dos incisiones o una incisión muy amplia.

- Menor dolor post-operatorio.
En el volumen XXVI, número dos de febrero de 2002 de Actas Urológicas ${ }^{2}$, presentamos nuestra experiencia con esta técnica, con una serie de ocho pacientes.

En el citado artículo insistíamos en lo defendido por otras series ${ }^{5,7}$, a la hora de utilizar dicha técnica:

- Ausencia de neoformaciones vesicales en el momento de la intervención.

- Localización tumoral en cálices, pelvis renal, o como mucho en el uréter proximal inmediatamente debajo de la unión pieloureteral.

- Tumores de bajo grado y estadio. 
Asímismo hacíamos referencia a que el riesgo de recidiva tumoral en el lecho de la desinserción es muy bajo ${ }^{1}$ si se siguen las premisas, antes establecidas, para la correcta indicación.

Durante el seguimiento post-quirúrgico de los pacientes, a los que se aplicó esta técnica posteriormente a la revisión, detectamos un caso en el cual a los 10 meses de la cirugía se había producido un crecimiento tumoral paravesical identificado posteriormente como una recidiva de carcinoma transicional en el lecho de desinserción.

\section{CASO CLÍNICO}

Se trata de un paciente de 79 años entre cuyos antecedentes de interés destaca un EPOC severo que requiere tratamiento con oxígeno domiciliario, y una intervención por carcinoma laríngeo en el año 1987 (controlado desde el punto de vista oncológico), todo ello secundario a su hábito tabáquico.
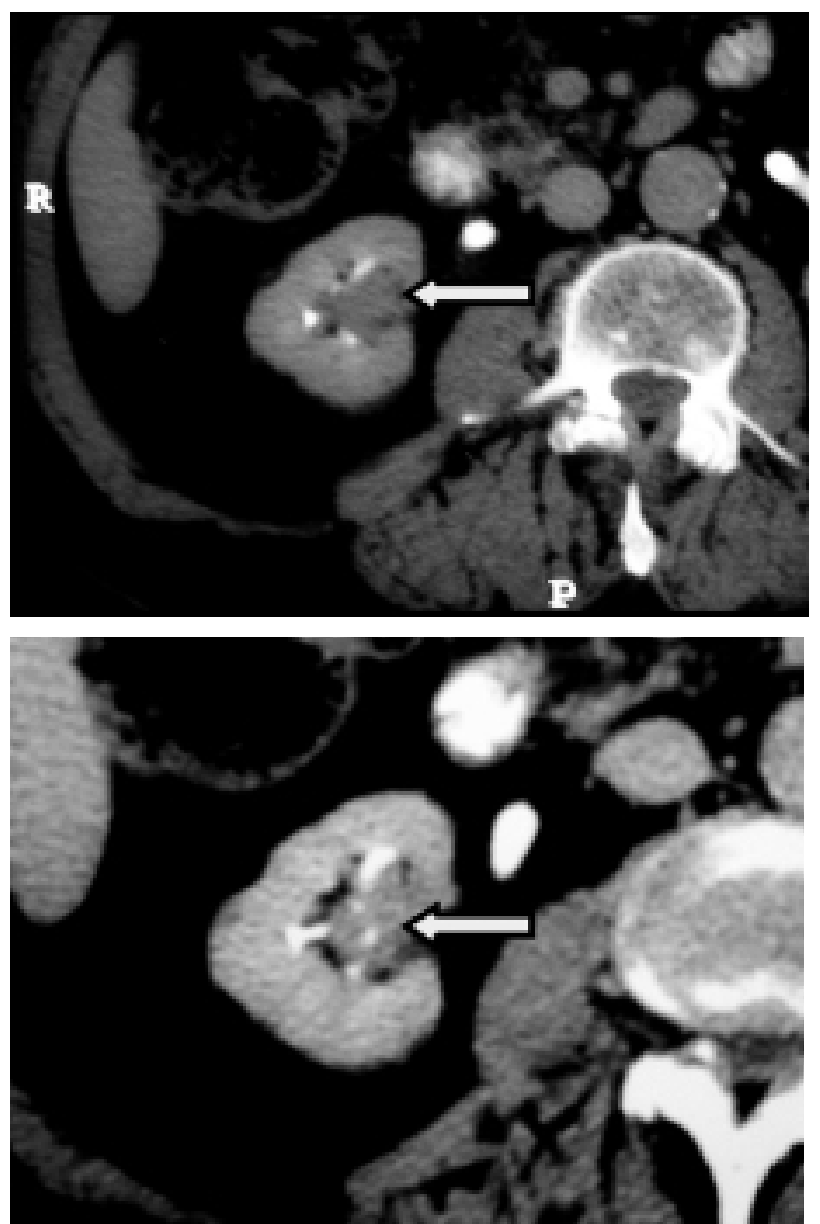

El paciente es remitido a su urólogo de zona por su médico de cabecera, por presentar una hematuria total monosintomática esporádica de tres meses de evolución.

A la exploración, tenía buen estado general con una palpación abdominal normal, y un tacto rectal con una próstata grado I sin sospecha de malignidad.

Interrogado acerca de su micción, refiere un sindrome prostático muy leve, que no necesita tratamiento y las hematurias esporádicas antes mencionadas. Percusión renal bilateral normal.

Su urólogo le solicita un estudio ecográfico con hallazgos poco precisos y que planteaban dudas diagnósticas, por lo que se decide la realización de una TAC.

Con dicha prueba es enviado a la consultas hospitalarias de urología, momento en el que entramos en contacto con el paciente (Fig. 1).
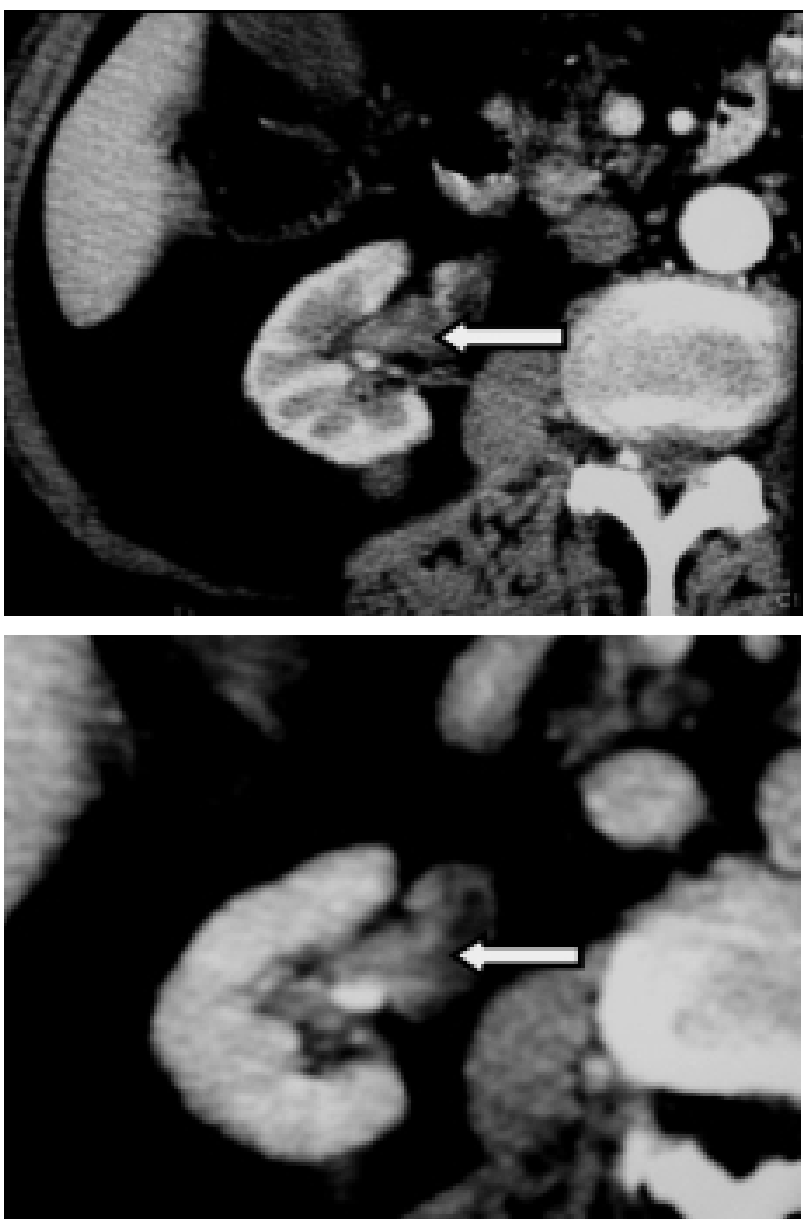

FIGURA 1. Cortes de TAC en los que se aprecia, distintas fases de concentración y eliminación de contraste, defecto de replección de gran tamaño que ocupa la totalidad de la pelvis del riñón izquierdo (flechas) el diagnóstico fue carcioma de células transicionales estadio T3, grado nuclear 2 con invasión de grasa de seno renal y de parénquima. 
En la TAC se aprecia un riñón izquierdo con dos quistes de unos $3 \mathrm{~cm}$ de diámetro, en sendos polos renales, y un riñón derecho con un quiste de $6 \mathrm{~cm}$ en el polo superior y una ocupación del seno renal por un tejido de aspecto blando con realce tras la administración intravenosa de contraste, con el diagnóstico radiológico de tumor de vías con afectación de pelvis renal. En dicha TAC no se describe afectación vesical, ni adenopatías retroperitoneales.

El estudio de extensión resulta normal, así como la valoración preanestésica.

La edad del paciente, la localización tumoral y la ausencia de tumor a nivel vesical, nos inclinan a plantear la cirugía radical con desinserción endoscópica.

No obstante, se solicitan citologías urinarias que resultan negativas.

Llegados a este punto se realiza la nefroureterectomía radical con desinserción endoscópica del uréter, en octubre de 2000, cirugía que se lleva a cabo sin complicaciones. El post-operatorio transcurre de manera favorable, retirando los drenajes a los 5 días, dando el alta al paciente al día siguiente, y retirando sonda vesical el décimo día tras la cirugía.

El estudio anatomopatológico de la pieza, resultó ser un carcinoma transicional sólido y papilar, medianamente diferenciado, que infiltra focalmente grasa peripiélica y parénquima renal (pT3 G2), así como displasia focal que afectaba al uréter.

Dada la edad del paciente se decide no llevar a cabo tratamiento quimioterápico adyuvante, a pesar del estadio tumoral.

El paciente es seguido en consultas, a la cual acude en junio de 2001, refiriendo algún episodio aislado de hematuria y dolor intenso en zona de fosa ilíaca derecha e hipogastrio. Se solicitan citologías urinarias que resultan negativas, y TAC de control.

Tras la realización de la TAC el paciente acude a urgencias por hematuria intensa de dos dias de evolución, que requiere ingreso y colocación de sistema lavador (Figs. 2 y 3 ).

En la TAC los hallazgos son los siguientes:

Imagen paravesical derecha de $3,5 \times 4,10 \mathrm{~cm}$ que se realza tras administrar contraste y que contacta con la pared vesical con impronta e invasión de la misma, compatible con recidiva tumoral.
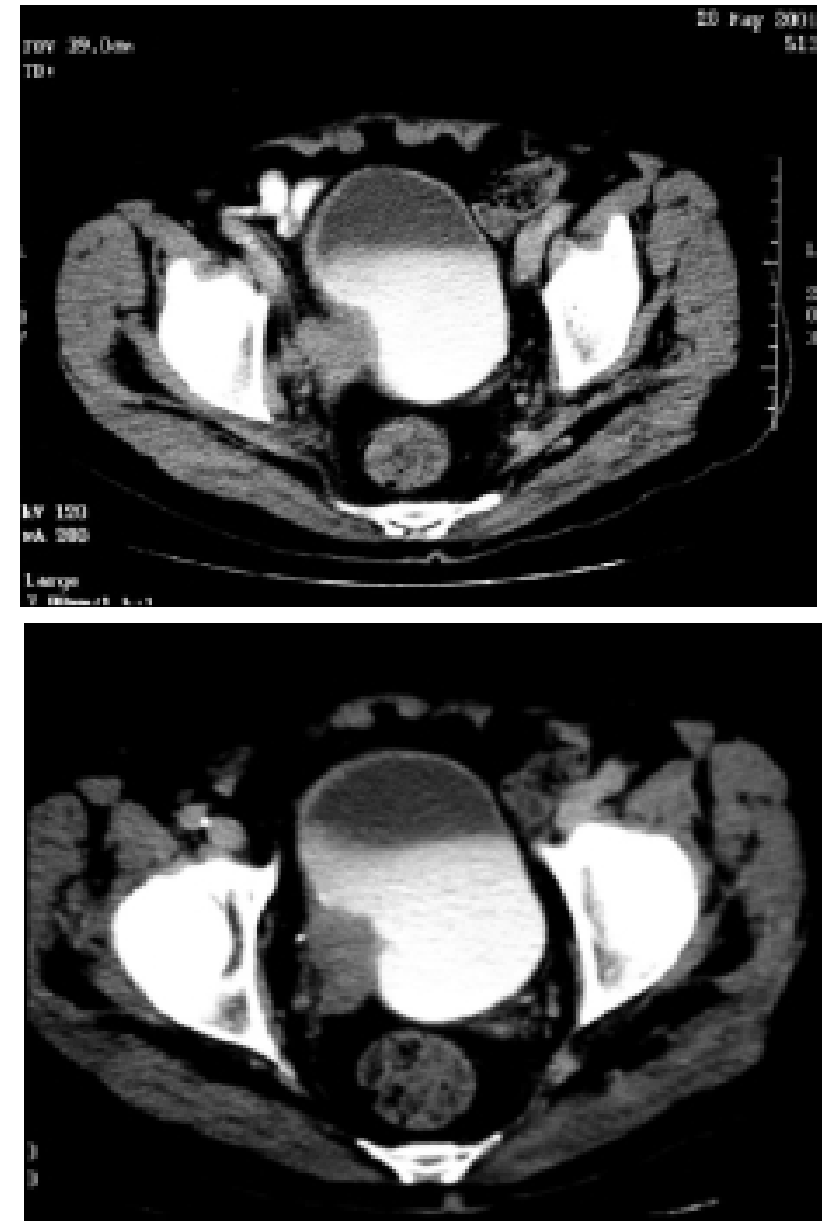

FIGURA 2. Cortes de TAC a nivel de pelvis en los que se aprecia imagen tumoral que comprime e infiltra la cara lateral derecha de vejiga y zona de hemitrigono derecho. El diagnóstico fue recidiva de carcinoma transicional muy indiferenciado.

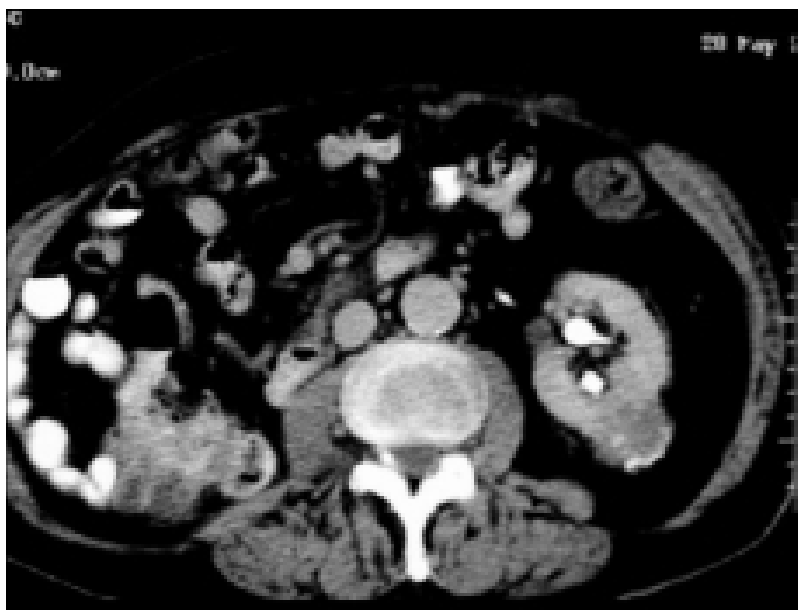

FIGURA 3. Cortes de TAC en los que se aprecia lesión quistica en polo inferior de riñón izquierdo, con zonas de realce de contraste en su interior, que hacen presuponer el diagnóstico de adenocarcinoma renal. 
Riñón izquierdo con las dos lesiones quísticas conocidas, sin embargo en la correspondiente a la del polo inferior se aprecia contenido sólido con leve realce al administrar contraste.

Nos encontramos ante el diagnóstico de un posible adenocarcinoma renal de polo inferior del único riñón del paciente, y una probable recidiva de carcinoma transicional a nivel paravesical que está provocando clínica álgica intensa y cuadro importante de hematuria.

Valorado el cuadro en conjunto, la edad y estado general del paciente, se decide realizar una exéresis paliativa de la recidiva, y no llevar a cabo actuación alguna sobre el hallazgo incidental del riñón izquierdo.

Así, en junio de 2001, a través de una laparotomía media infraumbilical transperitoneal, se realiza una exéresis de la masa perivesical y cistectomía parcial, dado que la tumoración infiltraba la cara lateral derecha vesical.

La evolución post-operatoria resulta favorable pudiendo ser dado de alta al $12^{\circ}$ día tras la cirugía y previa retirada de los drenajes.

El resultado anatomopatológico resultó un carcinoma urotelial sólido poco diferenciado, que infiltraba toda la pared vesical, afectando a tejido adiposo y vesícula seminal (pT3b grado nuclear 3).

En controles posteriores en consulta el paciente se encontraba bien de estado general, sin signos de recidiva en la ecografía de control y con función renal correcta.

En la actualidad se ha perdido el seguimiento del paciente por no acudir a la consulta sin poder determinar si se ha producido el fallecimiento del mismo.

\section{COMENTARIO}

La técnica de elección empleada en nuestro servicio para el tratamiento de los tumores transicionales de tracto urinario superior, es la nefroureterectomía radical con desinserción endoscópica del uréter, siempre que se cumplan las indicaciones aceptadas.
En el caso clínico descrito, se daban las condiciones adecuadas para llevar a cabo dicha técnica, sin embargo, el elevado estadio tumoral, así como el alto grado de indiferenciación, unidos a la presencia de displasia focal en el uréter ${ }^{6}$, fueron determinantes importantes en la recidiva tumoral en el lecho de desinserción.

Así mismo, la no administración de quimioterapia adyuvante por la edad y estado general del paciente condicionaron una disminución en la efectividad terapéutica.

\section{REFERENCIAS}

1. FERNÁNDEZ GÓMEZ JM, BARMADAH SE, PÉREZ GARCÍA J, RABADE REY CJ, RODRÍGUEZ MARTÍNEZ JJ.: Riesgo de implantación tumoral tras la nefroureterectomía combinada con resección endoscópica del meato ureteral. Arch Esp Urol 1998 oct; 51 (8): 829-831.

2. PASCUAL REGUEIRO D, TRÍVEZ BONED MA, GARCÍA GARCÍA MA, GARCÍA DE JALÓN MARTÍNEZ A, BLAS MARÍN M, RIOJA SANZ LA.: Desinserción ureteral endoscópica en la nefroureterectomía radical: presentación de nuestra experiencia. Act Uro Esp 2002 feb; 26 (2): 85-90.

3. BLOOM NA, VIDONE RA, LYTTON B.: Primary carcinoma of the ureter: a report of 102 new cases. $J$ Urol 1970; 103: 590.

4. KAKIZOE T, FUJITA J, MURASE T et al.: Transicional cell carcinoma of the bladder in patients with renal pelvic and ureteral cancer. Urol 124; 17: 1980.

5. LIN WC, LO KY, CHANG HK.: Single-incision nephroureterectomy combined with transurethral incision of bladder cuff for renal pelvic tumor. $J$ Formos Med Assoc 1991 sep; 90 (9): 840-843.

6. LEE SH, LIN JS, TZAI TS, CHOW NH, TONG YC, YANG WH, CHANG CC, CHENG HL.: Prognostic factors of primary transitional cell carcinoma of the upper urinary tract. Eur Urol 1996; 29 (3): 266-270; discussion 271.

7. SHENTAL J, ROZENMAN J, CHAIMOWITCH G, ALMOG D.: Nephroureterectomy through a single lumbar incision combined with endoscopic incision of a bladder cuff. Urol Int 1999; 62 (3): 147-149.

Dr. D. Pascual Regueiro

Avda. Compromiso de Caspe, 27-29, $2^{\circ}$ A

50002 Zaragoza

(Trabajo recibido el 18 noviembre de 2002) 